\title{
Isobolographic Analysis of The Antidepressant Interaction in Two-Drug Combinations of Citalopram, Bupropion and Scopolamine in Mice
}

Mohammad-Hossein Mohammadi-mahdiabadi-hasani

Tehran University of Medical Sciences

Mohaddeseh Ebrahimi-Ghiri ( $\triangle$ mebrahimi@znu.ac.ir)

Department of Biology, Faculty of Sciences, University of Zanjan, Zanjan, Iran

Fatemeh Khakpai

Islamic Azad University

Mohammad-Reza Zarrindast

Tehran University of Medical Sciences

\section{Research Article}

Keywords: Depression, Anxiety, Citalopram, Bupropion, Scopolamine

Posted Date: February 14th, 2022

DOI: https://doi.org/10.21203/rs.3.rs-1329278/v1

License: @ (i) This work is licensed under a Creative Commons Attribution 4.0 International License. Read Full License

Version of Record: A version of this preprint was published at Naunyn-Schmiedeberg's Archives of Pharmacology on April 19th, 2022. See the published version at https://doi.org/10.1007/s00210-02202242-2. 


\section{Abstract}

Depression and anxiety are psychiatric diseases that commonly occur together, and the patient burden and complexity increase when both are present. Comorbid anxiety and depression are often more resistant to common drug treatments such as antidepressants. Combination therapy is a suggested approach in treating these patients, where a decline of doses could reduce undesirable outcomes and still achieve optimal effects. We, therefore, conducted a preclinical study to assess the effect of two-drug combinations of citalopram, bupropion, and scopolamine on anxiety- and antidepressive-like behaviors in male NMRI mice and aimed to determine the nature of the interaction between components. Anxiety- or antidepressive-like activity of mice was assessed by the hole-board or forced swim test (FST), respectively. Our results revealed that citalopram (0.01- $0.25 \mathrm{mg} / \mathrm{kg}$; i.p.), bupropion (1-9 mg/kg; i.p.) or scopolamine (0.01-0.1 mg/kg; i.p.) diminished immobility time in the FST, suggesting an antidepressivelike effect. Citalopram decreased dead-dip counts in the hole-board, indicating an anxiogenic-like activity. All two-drug combinations, at inactive doses, exerted an antidepressive-like behavior. Only bupropion/scopolamine combination increased head-dip counts compared to the bupropion/saline group. Isobolographic analysis revealed an antidepressive synergy effect between citalopram plus bupropion, and an antidepressive additive impact between scopolamine plus citalopram or bupropion. It should be noted that the higher dose of each drug alone declined locomotor activity, while two-drug combinations did not affect this parameter. These results suggest a stronger antidepressive effect for citalopram/bupropion combination than other two-drug combinations.

\section{Introduction}

Depression and anxiety disorders are the major causes of morbidity that affect more than $16 \%$ of adults over their lifetime. Today, there is a wide array of antidepressants with robust efficacy to treat both mood and anxiety disorders (Ballenger 2000). The drugs most frequently prescribed for the treatment of these conditions are selective serotonin reuptake inhibitors (SSRIs) that bind serotonin (5-HT) transporters, leading to the accumulation of 5-HT and improvement of depression (Owens and Nemeroff 1994; Jin et al. 2017). However, in some patients, SSRIs are ineffective or only partially effective (Zimmerman et al. 2016). Citalopram, as an antidepressant agent within the SSRI class, has proven to be effective in treating major depression, other depressive disorders, and panic disorder. It may be effective in treating of other anxiety disorders, substance use disorders, and a few medical conditions (Bezchlibnyk-Butler et al. 2000). However, it has been reported that only about $30 \%$ of patients were recovering after 12 weeks of citalopram treatment (Trivedi et al. 2006).

Bupropion is an atypical antidepressant because its mechanisms of action differs from all other antidepressants (Piacentini et al. 2003). It acts through dual inhibition of norepinephrine and dopamine reuptake without altering serotonergic neurotransmission (Kavoussi et al. 1997). However, bupropion is as effective as other antidepressants, including SSRIs and tricyclic antidepressants (Huecker et al. 2021), without causing the adverse effects of common antidepressants. Therefore, bupropion is considered an antidepressant with unique pharmacologic properties with specific tolerability (Stahl et al. 2004). 
However, the exact mechanism as to how bupropion elicits antidepressant activity is still unclear (Kotagale et al. 2013).

Scopolamine is a nonselective muscarinic antagonist that produces relatively rapid antidepressant effects. The rapid antidepressant effect of scopolamine is thought to be linked to neuroplasticity within glutamatergic synapses (Drevets et al. 2020). Scopolamine also produces mixed effects in the anxietylike behavior of rodents. Extensive evidence has shown that scopolamine impairs attention, learning, and memory at the doses used to produce antidepressant effects (Klinkenberg and Blokland 2010).

In order to limit the potentially harmful effects of antidepressants and make them more effective, we hypothesized that a combination of low-dose medications could be a good option for treating depression. Therefore, we selected three drugs from different classes of antidepressants, including citalopram, bupropion, and scopolamine, and examined their effects on anxiety- and antidepressive-like behaviors of mice. Then, the interaction between inactive doses of two-drug combinations was investigated. Finally, the type of interaction was determined using the isobolographic analysis.

\section{Material And Methods}

\subsection{Experimental subjects}

Male adult NMRI mice (25-30 g) were obtained from the ICSS (Institute of Cognitive Sciences Studies, Tehran, Iran) breeding colony. Mice were housed in cages of eight at $22 \pm 2{ }^{\circ} \mathrm{C}$ in a 12 -h light/dark cycle (light on at 7:00 a.m.). Tap water and standard food pellets were available ad libitum. The study was conducted under experimental protocols approved by the Animal Care and Research Ethics Committee of Tehran University of Medical Sciences, Tehran, Iran. Housing and experimental procedures were conducted under the Guide for the Care and Use of Laboratory Animals (National Institutes of Health Publication No. 85-23, revised 2010).

\subsection{Drug solutions and administration}

Citalopram hydrobromide (Daroupakhsh, Tehran, Iran), bupropion hydrochloride (Sigma-Aldrich, St. Louis, MO, USA), and scopolamine hydrobromide (Tocris Bioscience; Bristol, UK) were dissolved in $0.9 \%$ saline and injected via intraperitoneal (i.p.) route. Control animals received saline $(10 \mathrm{ml} / \mathrm{kg})$. All solutions were freshly prepared before use and administered at a volume of $10 \mathrm{ml} / \mathrm{kg}$. To determinate the effect of co-administration of two components, they were administered i.p.; one immediately after the other, but not in the same solution. This was done to avoid a possible chemical interaction of two compounds in the same solution. Doses employed in the protocols were based upon our preliminary experiments and literature search.

\subsection{Hole-board test}

A hole-board test was conducted to evaluate locomotion and exploratory 
behavior of the mice (Nasehi et al. 2019; Ebrahimi-Ghiri et al. 2020b). Briefly, the testing apparatus was conducted using an opaque white acrylic board with 16 spaced holes located at equal distances from one another ( $3 \mathrm{~cm}$ diameter). The apparatus was elevated to a height of $15 \mathrm{~cm}$. Each mouse was placed in the middle of the floor to explore the holes on the device. The number of head dipping into the hole was recorded by photocells arranged below the holes. Head dipping behavior is sensitive to changes in the emotional state of the animal, and suggested that enhanced head-dipping behavior may indicate an anxiolytic state in animals (Kaur et al. 2021). To evaluate the locomotor activity, the ground area of the device was divided into four equal size squares. The number of crossings from one square to another was considered an index of locomotion and recorded by an experimenter.

\subsection{Forced swim test (FST)}

The cylindrical glass container $(25 \mathrm{~cm}$ height $\times 10 \mathrm{~cm}$ diameter) was filled with $19 \mathrm{~cm}$ high water $(25 \pm$ $1^{\circ} \mathrm{C}$ ), and the mice were individually dropped into the

water for $6 \mathrm{~min}$. The time of immobility was recorded during the last $4 \mathrm{~min}$ of the 6 -min testing period, thus after 2 min of latency. Each mouse was judged to be immobile when it remained floating passively, except those movements needed to hold its head beyond the water. A decrease in the duration of immobility is indicative of an antidepressant-like effect (Nasehi et al. 2019; Ebrahimi-Ghiri et al. 2020b).

\subsection{Experimental design}

The animals were randomly assigned to experimental groups containing eight mice each. Each animal was used only once. Behavioral tests were performed $30 \mathrm{~min}$ after the last administration. The interval between the two tests was one $h$.

\subsubsection{Determination of dose-response curve of citalopram, bupropion, and scopolamine in the hole-board and FST}

Ninety-six animals were randomly divided into three sets which each set consisting of four groups $(\mathrm{n}=8$ per each group). Four groups of the first set received different doses of citalopram $(0,0.01,0.05$ and 0.25 $\mathrm{mg} / \mathrm{kg})$. Four groups of the second set were administered by different doses of bupropion $(0,1,3$ and 9 $\mathrm{mg} / \mathrm{kg})$. Four groups of third set received scopolamine $(0,0.01,0.05$ and $0.1 \mathrm{mg} / \mathrm{kg})$.

\subsubsection{Interaction of two-drug components of citalopram, bupropion and scopolamine in the hole-board and FST}

Ninety-six animals were randomly divided into three sets which each set consisting of four groups $(\mathrm{n}=8$ per each group). Four groups of the first set received saline/saline, bupropion ( $1 \mathrm{mg} / \mathrm{kg}) / \mathrm{saline}$, saline/citalopram $(0.01 \mathrm{mg} / \mathrm{kg})$, and bupropion/citalopram, respectively. Four groups of the second set received saline/saline, scopolamine $(0.01 \mathrm{mg} / \mathrm{kg}) /$ saline, saline/citalopram $(0.01 \mathrm{mg} / \mathrm{kg})$, or scopolamine/citalopram, respectively. Four groups of the third set received saline/saline, scopolamine $(0.01 \mathrm{mg} / \mathrm{kg}) /$ saline, saline/bupropion $(1 \mathrm{mg} / \mathrm{kg})$ or scopolamine/bupropion, respectively. 


\subsubsection{Analysis of the type of interaction between a two-drug combination of citalopram, bupropion and scopolamine}

Interactions between two-drug components were assessed using an isobolographic analysis method [22]. At first, the ED50 value of each drug was calculated by linear regression analysis. In the next step, a combination of the two drugs was administered at fixed-dose fractions of the ED50 values (first drug ED 50/2 + second drug ED50/2 mg/kg; first drug ED50/4 + second drug ED50/4 mg/kg and first drug $\mathrm{ED} 50 / 8$ + second drug ED $50 / 8 \mathrm{mg} / \mathrm{kg}$ ). For drug combinations, the theoretic ED50 is first drug ED 50/2 + second drug ED50/2. Experimental values of drugs combination from fixed-ratio-designed studies were also analyzed using the regression analysis, after which the experimental ED50 value of the drug combination was calculated (50\% immobility time). The statistical significance between the theoretical ED50 and experimental ED50 of the drug combination was evaluated using the one-sample student's ttest. When the experimental ED50 was

significantly lower than the theoretical ED50, a supra-additive (synergistic) interaction between the first drug and the second drug could be inferred. At the same time, if there were no difference between them, this would indicate additive interaction rather than synergistic effect (Ebrahimi-Ghiri et al. 2020b). Therefore, seventy-two animals were randomly divided into three sets of three groups ( $n=8$ per each group). All groups were included as described below:

Three groups of the first set: bupropion $(0.37 \mathrm{mg} / \mathrm{kg}) /$ citalopram $(0.006 \mathrm{mg} / \mathrm{kg})$, bupropion $(0.74$ $\mathrm{mg} / \mathrm{kg}$ )/citalopram (0.012 mg/kg), and bupropion (1.48 mg/kg)/citalopram (0.024 mg/kg).

Three groups of the second set: scopolamine $(0.012 \mathrm{mg} / \mathrm{kg}) /$ citalopram $(0.006 \mathrm{mg} / \mathrm{kg})$, scopolamine $(0.024 \mathrm{mg} / \mathrm{kg}) /$ citalopram $(0.012 \mathrm{mg} / \mathrm{kg})$, and scopolamine $(0.048 \mathrm{mg} / \mathrm{kg}) /$ citalopram $(0.024 \mathrm{mg} / \mathrm{kg})$.

Three groups of the third set: scopolamine $(0.012 \mathrm{mg} / \mathrm{kg}) /$ bupropion $(0.37 \mathrm{mg} / \mathrm{kg})$, scopolamine $(0.024$ $\mathrm{mg} / \mathrm{kg}) / \mathrm{bupropion}(0.74 \mathrm{mg} / \mathrm{kg})$, and scopolamine $(0.048 \mathrm{mg} / \mathrm{kg}) / \mathrm{bupropion}(1.48 \mathrm{mg} / \mathrm{kg})$.

\subsection{Statistical calculations}

Data are presented as mean \pm standard error of the mean (SEM). The statistical analyses were performed using one-way Analysis of Variance (ANOVA) followed by the Tukey test (when one drug was given), or two-way ANOVA with a comparison between individual groups by Tukey post hoc test (when two drugs were used). The difference between theoretical ED50 and experimental ED50 was examined by Student's t-test. Two regression lines were compared by test for comparing (slopes and intercepts) of two regression lines. Results were considered significant when the probability values were less than $0.05(\mathrm{P}<$ 0.05).

\section{Results}




\subsection{The effects of citalopram, bupropion or scopolamine on the performance of mice in the hole-board and FST}

Citalopram at the doses of 0.05 and $0.25 \mathrm{mg} / \mathrm{kg}$ significantly decreased immobility time in the FST [F ( 3 , $28)=10.017, \mathrm{P}<.001 ;$ Fig. 1. A]. Citalopram at the dose of $0.25 \mathrm{mg} / \mathrm{kg}$ decreased head-dip counts $[\mathrm{F}(3$, $28)=5.710, P=.004$; Fig. 1. B], and locomotor activity $[F(3,28)=14.581, P<0.001$; Fig. 1. C] in the holeboard apparatus.

[Insert Fig. 1 here] and [Raw data in supplemental data]

Bupropion at the dose of $9 \mathrm{mg} / \mathrm{kg}$ significantly decreased immobility time in the FST $[\mathrm{F}(3,28)=6.327, \mathrm{P}$ $=.002$; Fig. 2A]. Bupropion at the doses of 3 and $9 \mathrm{mg} / \mathrm{kg}$ decreased locomotor activity $[\mathrm{F}(3,28)=$ 13.638, $\mathrm{P}<.001$; Fig. $2 \mathrm{C}]$, while it did not alter head-dip counts $[\mathrm{F}(3,28)=0.544, \mathrm{P}=0.656$; Fig. $2 \mathrm{~B}]$ in the hole-board apparatus.

[Insert Fig. 2 here] and [Raw data in supplemental data]

Scopolamine at the dose of $0.1 \mathrm{mg} / \mathrm{kg}$ significantly decreased immobility time in the $\operatorname{FST}[\mathrm{F}(3,28)=$ 24.442, $\mathrm{P}<.001$; Fig. 3A]. Scopolamine at the doses of 0.05 and $0.1 \mathrm{mg} / \mathrm{kg}$ decreased locomotor activity $[F(3,28)=8.919, P<.001$; Fig. $3 C]$, while it did not alter head-dip counts $[F(3,28)=1.823, P=0.166$; Fig. $3 \mathrm{~B}]$ in the hole-board apparatus.

[Insert Fig. 3 here] and [Raw data in supplemental data]

In summary, citalopram, bupropion, and scopolamine induced an antidepressant-like activity in the FST. Only citalopram exerted an anxiogenic-like behavior in the hole-board apparatus. All agents decreased locomotor activity.

\subsection{Interaction of two-drug components of citalopram, bupropion, or scopolamine in the hole-board and FST}

Binary compound of citalopram and bupropion significantly decreased immobility time in the FST (citalopram effect: $F(1,28)=16.374, P<0.001$; bupropion effect: $F(1,28)=19.739, P<0.001$; citalopram/bupropion interaction effect: $F(1,28)=6.571, P=0.016]$; Fig. $4 \mathrm{~A}$ ) compared to the saline/saline, saline/citalopram or bupropion/saline group. there was no significant interaction between citalopram and bupropion on head-dip counts (citalopram effect: $F(1,28)=0.856, P=0.363$; bupropion effect: $F(1,28)=0.856, P=0.363$; citalopram/bupropion interaction effect: $F(1,28)=1.773, P=0.194]$; Fig. 4B) and locomotor activity (citalopram effect: $F(1,28)=1.315, P=0.261$; bupropion effect: $F(1,28)$ $=0.584, \mathrm{P}=0.451$; citalopram/bupropion interaction effect: $\mathrm{F}(1,28)=0.016, \mathrm{P}=0.900]$; Fig. $4 \mathrm{C}$ ).

[Insert Fig. 4 here] and [Raw data in supplemental data] 
Binary compound of citalopram and scopolamine significantly decreased immobility time in the FST (citalopram effect: $F(1,28)=17.342, P<0.001$; scopolamine effect: $F(1,28)=31.892, P<0.001$; citalopram/scopolamine interaction effect: $F(1,28)=13.992, P=0.001]$; Fig. $5 \mathrm{~A}$ ) compared to the saline/saline, saline/citalopram or scopolamine/saline group. There was no significant interaction between citalopram and scopolamine on head-dip counts (citalopram effect: $F(1,28)=1.342, P=0.257$; scopolamine effect: $F(1,28)=0.010, P=0.922$; citalopram/scopolamine interaction effect: $F(1,28)=$ 2.523, $P=0.123$ ]; Fig. 5B) and locomotor activity (citalopram effect: $F(1,28)=4.483, P=0.043$; scopolamine effect: $F(1,28)=1.684, P=0.205$; citalopram/scopolamine interaction effect: $F(1,28)=$ $0.467, \mathrm{P}=0.500]$; Fig. 5C).

[Insert Fig. 5 here] and [Raw data in supplemental data]

Binary compound of bupropion and scopolamine significantly decreased immobility time in the FST (bupropion effect: $F(1,28)=15.471, P=0.001$; scopolamine effect: $F(1,28)=18.455, P<0.001$; bupropion/scopolamine interaction effect: $F(1,28)=4.873, P=0.036$ ]; Fig. $6 \mathrm{~A}$ ) compared to the saline/saline, saline/citalopram or scopolamine/saline group. Binary compound of bupropion and scopolamine significantly increased head-dip counts (bupropion effect: $F(1,28)=0.323, P=0.574$; scopolamine effect: $F(1,28)=2.160, P=0.153$; bupropion/scopolamine interaction effect: $F(1,28)=$ $10.203, P=0.003]$; Fig. $6 \mathrm{~B}$ ) compared to the bupropion/saline group. In addition, there was a significant interaction between bupropion and scopolamine on locomotor activity (bupropion effect: $F(1,28)=$ $0.387, \mathrm{P}=0.539$; scopolamine effect: $\mathrm{F}(1,28)=2.106, \mathrm{P}=0.158$; bupropion/scopolamine interaction effect: $F(1,28)=5.202, P=0.030]$; Fig. $6 C)$.

[Insert Fig. 6 here] and [Raw data in supplemental data]

In summary, binary compounds of citalopram, bupropion, or scopolamine exerted an antidepressant-like activity. Only the bupropion/scopolamine group induced an anxiolytic-like behavior compared to the bupropion/saline group.

\subsection{Synergistic antidepressant effect of citalopram/bupropion combination against the additive antidepressant effect of citalopram/scopolamine and bupropion/scopolamine combinations}

The theoretical and experimental ED50 of citalopram and bupropion, when co-injected, were compared by isobolographic analysis. The t-test revealed a significant difference among the experimental and theoretical ED50 in the FST $[\mathrm{t}(31)=16.098, \mathrm{P}<0.001]$; thus, citalopram/bupropion combination presents a synergistic interaction.

[Insert Fig. 7 here] and [Raw data in supplemental data] 
Similarly, isobologram analysis showed an additive antidepressant effect for citalopram/scopolamine combination [t $(31)=0.269, \mathrm{P}=0.789]$.

[Insert Fig. 8 here] and [Raw data in supplemental data]

T-test also showed an additive antidepressant effect for bupropion/scopolamine combination [t (31) = $0.077, P=0.939]$.

[Insert Fig. 9 here] and [Raw data in supplemental data] _-_-_-In summary, isobologtaphic analysis revealed a synergistic effect between citalopram and bupropion, and an additive effect between scopolamine and citalopram or bupropion in the FST.

\section{Discussion}

The presented research aimed to evaluate the anxiety- and antidepressive-like efficacies of two-drug combinations of citalopram, bupropion, and scopolamine in mice.

Our results provide evidence that citalopram, an SSIR antidepressant medication, significantly decreased immobility time in the FST, indicating an antidepressive-like efficacy. The higher dose of citalopram decreased head-dip counts in the hole-board apparatus, proposing an anxiogenic-like activity. Because the same dose of citalopram reduced locomotor activity, it is likely to affected anxiety-like behavior. Citalopram is the most frequently used antidepressant in clinical practice for the treatment of depression. It is effective in the treatment of depression related to Parkinson disease (Menza et al. 2004), poststroke depression (Karaiskos et al. 2012), depression in dementia (Nyth and Gottfries 1990), and perimenopausal and postmenopausal women with depression (Soares et al. 2003). In addition, prescribing citalopram to treat depression in patients with Parkinson disease or poststroke depression improves anxiety (Menza et al. 2004; Karaiskos et al. 2012). Lenz et al. proposed that citalopram is efficacious in managing acute anxiety disorders in elderly persons, as they had a significant amelioration in anxiety symptoms over eight weeks of treatment (Lenze et al. 2005). Acute administration of citalopram precipitated anxiety in the fear-potentiated startle, while its repeated administration decreases aversive states in healthy participants (Grillon et al. 2007; Grillon et al. 2009). Clinical evidence suggests a biphasic response of citalopram on antidepressive behaviors. One study demonstrated anxiogenic and anxiolytic effects of citalopram in rodents (Mombereau et al. 2010). Overall, the type of task used, the genetic difference of the studied subjects, and acute or repeated administration are essential factors in rodent anxiety response to SSRIs (Pollier et al. 2000). For example, Matto and coworkers demonstrated that acute citalopram administration in the open field test and repeated citalopram administration in the exploration box test attenuate rat exploratory behavior. However, these effects may not be implicated with increased anxiety or altered dopamine D2 receptor characteristics (Matto and Allikmets 1999). Citalopram inhibits the reuptake of $5-\mathrm{HT}$ in the brain and relatively limited effects on the neuronal reuptake of norepinephrine and dopamine (Misrani et al. 2019). 
We observed an antidepressant-like activity for acute administration of bupropion in mice, while it did not alter anxiety-like property compared to the saline control group. Meanwhile, two higher doses of bupropion decreased locomotor activity compared to the saline control group. Antidepressant efficacy of bupropion in clinical studies was reviewed by Patel and colleagues (Patel et al. 2016). A review study provided evidence for anxiolytic property of bupropion in human studies (Hernández-Lozano et al. 2010). Bupropion has been shown to reduce immobility in behavioral despair (Martin et al. 1990), and tailsuspension tests (Ripoll et al. 2003), and to attenuate behavioral impairments in a chronic-stress paradigm (Katz and Sibel 1982). Some studies have highlighted the importance of genetic factors in assessing the antidepressant effects of bupropion in animal models of depression (Ripoll et al. 2003). The effect of bupropion on anxiety is complex and depends on a variety of factors. Preclinical research has documented anxiogenic, anxiolytic, or ineffective responses by bupropion (Carrasco et al. 2004; Redolat et al. 2005; Dwoskin et al. 2006). Its antidepressant actions may engage nonselective reuptake of dopamine and noradrenaline in brain regions that modulate emotions. In addition, bupropion can affect the serotonergic system and also act as a cholinergic nicotine receptor antagonist (Hernández-Lozano et al. 2010).

Our results confirmed that scopolamine has an antidepressive-like profile. Although scopolamine did not significantly alter the performance of mice in the hole-board apparatus compared to the saline control group, it showed a slight tendency to develop anxiolytic behavior. It also reduced the locomotor activity of mice. Despite the ample clinical and preclinical evidence of the antidepressant property of scopolamine (Drevets and Furey 2010; Nasehi et al. 2019), there is limited evidence available for its effect on anxiety behaviors. The anxiogenic, anxiolytic, or no effects for scopolamine in different tasks have been reported (Klinkenberg and Blokland 2010). Our previous studies demonstrated that scopolamine produced an anxiogenic-like response in the EPM (Ebrahimi-Ghiri et al. 2020a), while it did not affect the anxietyrelated parameter in the hole-board apparatus (Nasehi et al. 2019). It seems that the dose of scopolamine, administration route, type of used task, or the strain of subject affect the response of drug on anxiety-related behaviors. The mechanisms associated with the antidepressant efficacy of scopolamine have been suggested to involve a-Amino-3-hydroxy-5-methyl-4-isoxazolepropionic acid (AMPA) receptor and mammalian target of rapamycin (mTOR) signaling (Martin et al. 2017).

In the next step, we observed that co-administration of inactive doses of citalopram and bupropion significantly decreased immobility time in the FST, while it did not alter hole-board parameters compared to the saline control group or each drug alone. The few studies that have evaluated the use of bupropion and citalopram are generally positive. One review showed that the combination of the bupropion and SSRI drugs are well tolerated, can improve the overall antidepressant response and, perhaps most importantly, can reduce or negate the side effects of SSRI drugs (e.g., weight gain and sexual side effects) (Patel et al. 2016). Bupropion, arguably, has had a more significant role in clinical practice as a co-prescribed antidepressant. It has been suggested that bupropion augments the serotonergic drug (es)citalopram effect (Patel et al. 2016). Another study that specifically looked at the combination of bupropion and citalopram had similar results. The combination was more effective than either drug alone and there was no increased incidence of side effects (Lam et al. 2004). Due to the mechanisms of 
citalopram and bupropion, they seem to potentiate each other through common pathways and create a more substantial antidepressant effect.

In the present study, co-administration of low doses of citalopram and scopolamine produced an antidepressive-like property. Incongruent with our finding, one study reported that scopolamine augments the citalopram effect to reduce immobility time in the forced swim assay (Martin et al. 2017). In the clinic, orally administered scopolamine has shown efficacy as an augmenting agent to the citalopram in major depression disorder patients (Khajavi et al. 2012). The researchers found that the combination of scopolamine and citalopram was effective in patients with depression, and that citalopram exerted no significant difference regarding the onset time of the antidepressant effects (Furey et al. 2013).

Results from our experiment indicated that a binary combination of bupropion and scopolamine has an antidepressive-like activity. Meanwhile, the combination increased head-dip counts compared to the bupropion/saline group in the hole-board apparatus. A search of scientific sites found no evidence of a combined effect of bupropion and scopolamine on anxiety- and antidepressive-like behaviors. Due to their mechanisms of action on different neurotransmitter systems, bupropion and scopolamine are likely to interact at the level of a downstream molecule and produce a more enormous antidepressant response.

Finally, we observed an antidepressant synergistic effect between citalopram and bupropion combination. However, isobologram analysis indicated an additive antidepressant effect between citalopram and scopolamine combination, and bupropion and scopolamine combination. In line with our observation, citalopram in combination with scopolamine exhibited addictive effect compared to scopolamine per se and citalopram per se (Singh and Singh 2015).

\section{Conclusion}

Citalopram, bupropion or scopolamine (antidepressant medications in three different classes) exerted an antidepressive-like activity. Binary combinations of the above drugs, at an inactive dose, had an antidepressive property. Isobolographic analysis indicated synergy between citalopram and bupropion on antidepressive-like behavior. Scopolamine in combination with citalopram or bupropion showed an additive antidepressive-like profile. Citalopram and bupropion combination, due to greater antidepressant efficacy, is a better choice for treating depressive disorders than the other two combinations.

\section{Declarations}

\section{Ethical approval}

The study was conducted under experimental protocols approved by the Animal Care and Research Ethics Committee of Tehran University of Medical Sciences, Tehran, Iran. Housing and experimental procedures were conducted under the Guide for the Care and Use of Laboratory Animals (National Institutes of Health Publication No. 85-23, revised 2010). 
Consent to Participate

Not applicable

Consent to Publish

Not applicable

Authors Contributions

MHMMH conducted experiments. ME conceived and designed research in addition to writing of the manuscript. FK and MRZ analyzed data. The authors declare that all data were generated in-house and that no paper mill was used.

Funding

The authors declare that no funds, grants, or other support were received during the preparation of this manuscript.

Competing Interests

The authors have no relevant financial or non-financial interests to disclose.

Availability of data and materials

Raw data were presented in the supplementary material.

\section{References}

1. Ballenger JC (2000) Anxiety and Depression: Optimizing Treatments. Prim Care Companion J Clin Psychiatry 2:71-79. doi: 10.4088/pcc.v02n0301

2. Bezchlibnyk-Butler K, Aleksic I, Kennedy SH (2000) Citalopram-a review of pharmacological and clinical effects. J Psychiatry Neurosci 25:241-254.

3. Carrasco MC, Vicens P, Vidal J, Redolat R (2004) Effects of acute administration of bupropion on behavior in the elevated plus-maze test by NMRI mice. Prog Neuropsychopharmacol Biol Psychiatry 28:1135-1141. doi: 10.1016/j.pnpbp.2004.06.005

4. Drevets WC, Bhattacharya A, Furey ML (2020) The antidepressant efficacy of the muscarinic antagonist scopolamine: Past findings and future directions. Adv Pharmacol 89:357-386. doi: 10.1016/bs.apha.2020.04.002

5. Drevets WC, Furey ML (2010) Replication of scopolamine's antidepressant efficacy in major depressive disorder: a randomized, placebo-controlled clinical trial. Biol Psychiatry 67:432-438. doi: 10.1016/j.biopsych.2009.11.021 
6. Dwoskin LP, Rauhut AS, King-Pospisil KA, Bardo MT (2006) Review of the pharmacology and clinical profile of bupropion, an antidepressant and tobacco use cessation agent. CNS Drug Rev 12:178207. doi: $10.1111 /$ j.1527-3458.2006.00178.x

7. Ebrahimi-Ghiri M, Khakpai F, Zarrindast M-R (2020a) Combined treatment of scopolamine and group III mGluR antagonist, CPPG, exerts antidepressant activity without affecting anxiety-related behaviors. Physiol Behav 224:113034. doi: 10.1016/j.physbeh.2020.113034

8. Ebrahimi-Ghiri M, Mohammadi-Mahdiabadi-Hasani MH, Nasehi M, Zarrindast MR (2020b) Better antidepressant efficacy of mecamylamine in combination with L-NAME than with L-arginine. Behav Brain Res 386:112604. doi: 10.1016/j.bbr.2020.112604

9. Furey ML, Drevets WC, Hoffman EM, et al (2013) Potential of pretreatment neural activity in the visual cortex during emotional processing to predict treatment response to scopolamine in major depressive disorder. JAMA psychiatry 70:280-290. doi: 10.1001/2013.jamapsychiatry.60

10. Grillon C, Chavis C, Covington MF, Pine DS (2009) Two-week treatment with the selective serotonin reuptake inhibitor citalopram reduces contextual anxiety but not cued fear in healthy volunteers: a fear-potentiated startle study. Neuropsychopharmacol Off Publ Am Coll Neuropsychopharmacol 34:964-971. doi: 10.1038/npp.2008.141

11. Grillon C, Levenson J, Pine DS (2007) A single dose of the selective serotonin reuptake inhibitor citalopram exacerbates anxiety in humans: a fear-potentiated startle study. Neuropsychopharmacol Off Publ Am Coll Neuropsychopharmacol 32:225-231. doi: 10.1038/sj.npp.1301204

12. Hernández-Lozano M, Gutiérrez-García AG, Contreras CM, Alcántara-López MG (2010) Effects of bupropion on depression, anxiety and smoking cessation. Arch Neurociencias 15:260-266.

13. Huecker MR, Smiley A, Saadabadi A (2021) Bupropion. Treasure Island (FL),

14. Jin Z-L, Chen X-F, Ran Y-H, et al (2017) Mouse strain differences in SSRI sensitivity correlate with serotonin transporter binding and function. Sci Rep 7:8631. doi: 10.1038/s41598-017-08953-4

15. Karaiskos D, Tzavellas E, Spengos K, et al (2012) Duloxetine versus citalopram and sertraline in the treatment of poststroke depression, anxiety, and fatigue. J Neuropsychiatry Clin Neurosci 24:349353. doi: 10.1176/appi.neuropsych. 11110325

16. Katz RJ, Sibel M (1982) Animal model of depression: tests of three structurally and pharmacologically novel antidepressant compounds. Pharmacol Biochem Behav 16:973-977. doi: 10.1016/0091-3057(82)90055-7

17. Kaur D, Shri R, Kamboj A (2021) Bioactivity-directed isolation, characterization, and quantification of an anxiolytic flavonoid from Brassica oleracea L. J Food Biochem 45:e13608. doi: $10.1111 / \mathrm{jfbc} .13608$

18. Kavoussi RJ, Segraves RT, Hughes AR, et al (1997) Double-blind comparison of bupropion sustained release and sertraline in depressed outpatients. J Clin Psychiatry 58:532-537. doi: 10.4088/jcp.v58n1204

19. Khajavi D, Farokhnia M, Modabbernia A, et al (2012) Oral scopolamine augmentation in moderate to severe major depressive disorder: a randomized, double-blind, placebo-controlled study. J Clin 
Psychiatry 73:1428-1433. doi: 10.4088/JCP.12m07706

20. Klinkenberg I, Blokland A (2010) The validity of scopolamine as a pharmacological model for cognitive impairment: a review of animal behavioral studies. Neurosci Biobehav Rev 34:1307-1350. doi: 10.1016/j.neubiorev.2010.04.001

21. Kotagale NR, Tripathi SJ, Aglawe MM, et al (2013) Evidences for the agmatine involvement in antidepressant like effect of bupropion in mouse forced swim test. Pharmacol Biochem Behav 107:42-47. doi: 10.1016/j.pbb.2013.03.019

22. Lam RW, Hossie H, Solomons K, Yatham LN (2004) Citalopram and bupropion-SR: combining versus switching in patients with treatment-resistant depression. J Clin Psychiatry 65:337-340.

23. Lenze EJ, Mulsant BH, Shear MK, et al (2005) Efficacy and tolerability of citalopram in the treatment of late-life anxiety disorders: results from an 8-week randomized, placebo-controlled trial. Am J Psychiatry 162:146-150. doi: 10.1176/appi.ajp.162.1.146

24. Martin AE, Schober DA, Nikolayev A, et al (2017) Further Evaluation of Mechanisms Associated with the Antidepressantlike Signature of Scopolamine in Mice. CNS Neurol Disord Drug Targets 16:492500. doi: $10.2174 / 1871527316666170309142646$

25. Martin P, Massol J, Colin JN, et al (1990) Antidepressant profile of bupropion and three metabolites in mice. Pharmacopsychiatry 23:187-194. doi: 10.1055/s-2007-1014505

26. Matto V, Allikmets $L$ (1999) Acute and chronic citalopram treatment differently modulates rat exploratory behavior in the exploration box test: no evidence for increased anxiety or changes in the [3H]raclopride binding. Pharmacology 58:59-69. doi: 10.1159/000028269

27. Menza M, Marin H, Kaufman K, et al (2004) Citalopram treatment of depression in Parkinson's disease: the impact on anxiety, disability, and cognition. J Neuropsychiatry Clin Neurosci 16:315319. doi: 10.1176/jnp.16.3.315

28. Misrani A, Tabassum S, Chen X, et al (2019) Differential effects of citalopram on sleep-deprivationinduced depressive-like behavior and memory impairments in mice. Prog Neuropsychopharmacol Biol Psychiatry 88:102-111. doi: 10.1016/j.pnpbp.2018.07.013

29. Mombereau C, Gur TL, Onksen J, Blendy JA (2010) Differential effects of acute and repeated citalopram in mouse models of anxiety and depression. Int J Neuropsychopharmacol 13:321-334. doi: $10.1017 /$ S1461145709990630

30. Nasehi M, Mohammadi-Mahdiabadi-Hasani M-H, Ebrahimi-Ghiri M, Zarrindast M-R (2019) Additive interaction between scopolamine and nitric oxide agents on immobility in the forced swim test but not exploratory activity in the hole-board. Psychopharmacology (Berl). doi: 10.1007/s00213-01905294-0

31. Nyth AL, Gottfries CG (1990) The clinical efficacy of citalopram in treatment of emotional disturbances in dementia disorders. A Nordic multicentre study. Br J Psychiatry 157:894-901. doi: 10.1192/bjp.157.6.894

32. Owens MJ, Nemeroff CB (1994) Role of serotonin in the pathophysiology of depression: focus on the serotonin transporter. Clin Chem 40:288-295. 
33. Patel K, Allen S, Haque MN, et al (2016) Bupropion: a systematic review and meta-analysis of effectiveness as an antidepressant. Ther Adv Psychopharmacol 6:99-144. doi:

$10.1177 / 2045125316629071$

34. Piacentini MF, Clinckers R, Meeusen R, et al (2003) Effect of bupropion on hippocampal neurotransmitters and on peripheral hormonal concentrations in the rat. J Appl Physiol 95:652-656. doi: 10.1152/japplphysiol.01058.2002

35. Pollier F, Sarre S, Aguerre S, et al (2000) Serotonin reuptake inhibition by citalopram in rat strains differing for their emotionality. Neuropsychopharmacol Off Publ Am Coll Neuropsychopharmacol 22:64-76. doi: 10.1016/S0893-133X(99)00092-5

36. Redolat R, Gómez MC, Vicens P, Carrasco MC (2005) Bupropion effects on aggressiveness and anxiety in OF1 male mice. Psychopharmacology (Berl) 177:418-427. doi: 10.1007/s00213-0041965-9

37. Ripoll N, David DJP, Dailly E, et al (2003) Antidepressant-like effects in various mice strains in the tail suspension test. Behav Brain Res 143:193-200. doi: 10.1016/s0166-4328(03)00034-2

38. Singh P, Singh TG (2015) Modulation of muscarinic system with serotonin-norepinephrine reuptake inhibitor antidepressant attenuates depression in mice. Indian J Pharmacol 47:388-393. doi: $10.4103 / 0253-7613.161260$

39. Soares CN, Poitras JR, Prouty J, et al (2003) Efficacy of citalopram as a monotherapy or as an adjunctive treatment to estrogen therapy for perimenopausal and postmenopausal women with depression and vasomotor symptoms. J Clin Psychiatry 64:473-479. doi: 10.4088/jcp.v64n0419

40. Stahl SM, Pradko JF, Haight BR, et al (2004) A Review of the Neuropharmacology of Bupropion, a Dual Norepinephrine and Dopamine Reuptake Inhibitor. Prim Care Companion J Clin Psychiatry 6:159-166. doi: 10.4088/pcc.v06n0403

41. Trivedi MH, Rush AJ, Wisniewski SR, et al (2006) Evaluation of outcomes with citalopram for depression using measurement-based care in STAR*D: implications for clinical practice. Am J Psychiatry 163:28-40. doi: 10.1176/appi.ajp.163.1.28

42. Zimmerman M, Multach M, Walsh E, et al (2016) Problems in the Descriptions of the Psychiatric Inclusion and Exclusion Criteria in Publications of Antidepressant Efficacy Trials: A Qualitative Review and Recommendations for Improved Clarity. CNS Drugs 30:185-191. doi: 10.1007/s40263016-0314-y

\section{Figures}



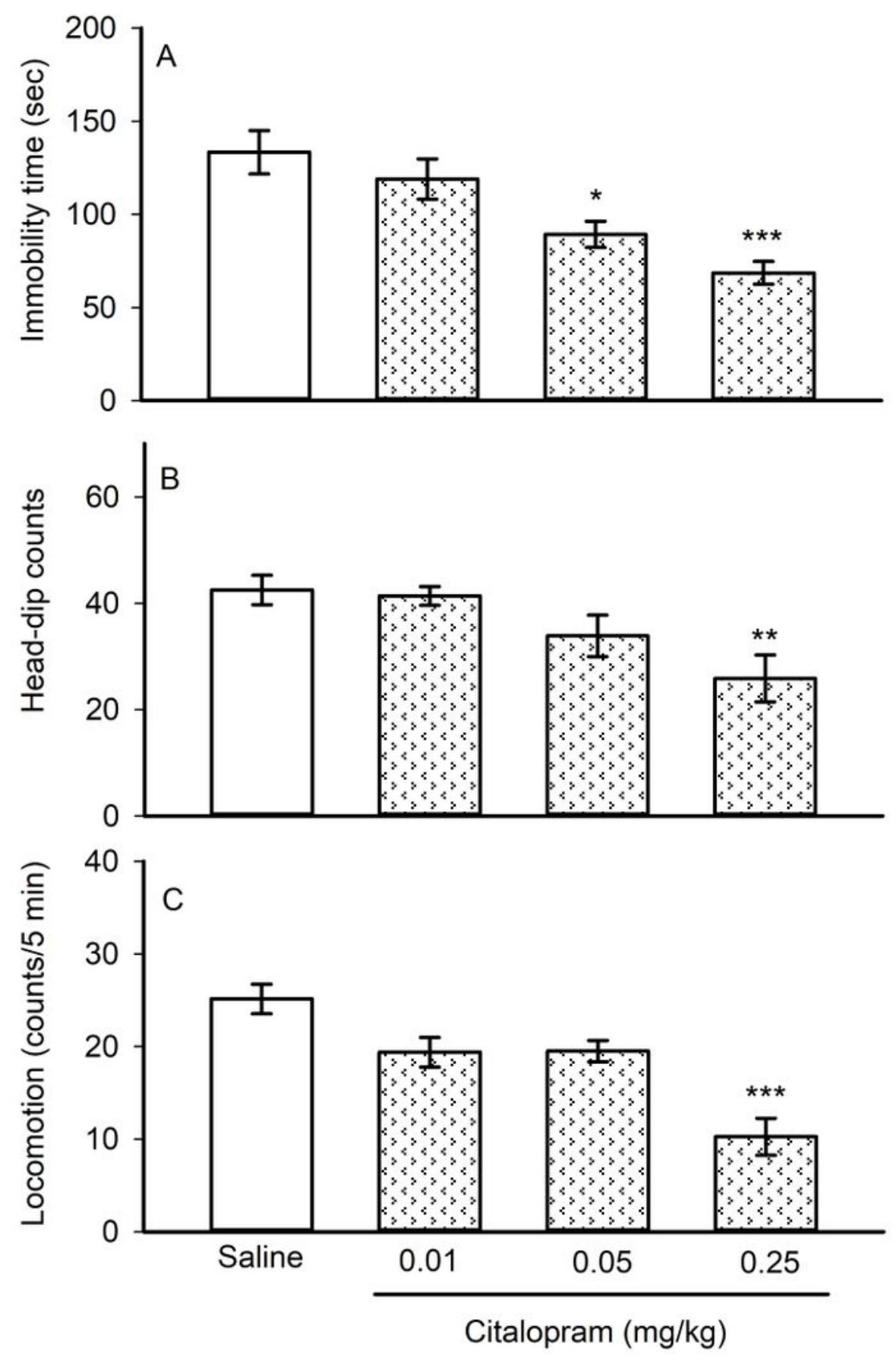

Fig. 1

\section{Figure 1}

Effect of citalopram on mice performance in the FST and hole-board apparatus. Citalopram $(0.01,0.05$ and $0.25 \mathrm{mg} / \mathrm{kg}$; i.p.) was administered i.p. $30 \mathrm{~min}$ before the behavioral tests. Control animals received saline (10 $\mathrm{ml} / \mathrm{kg}$, i.p.). (A) immobility time in the FST, (B) head-dip counts and (C) locomotor activity in the hole-board apparatus. Bars represented means \pm SEM of eight mice. ${ }^{\star \star \star} P<0.001,{ }^{\star} \mathrm{P} P<0.01$, and ${ }^{*} P<0.5$ versus saline group according to one-ANOVA followed by Tukey post-hoc test. 

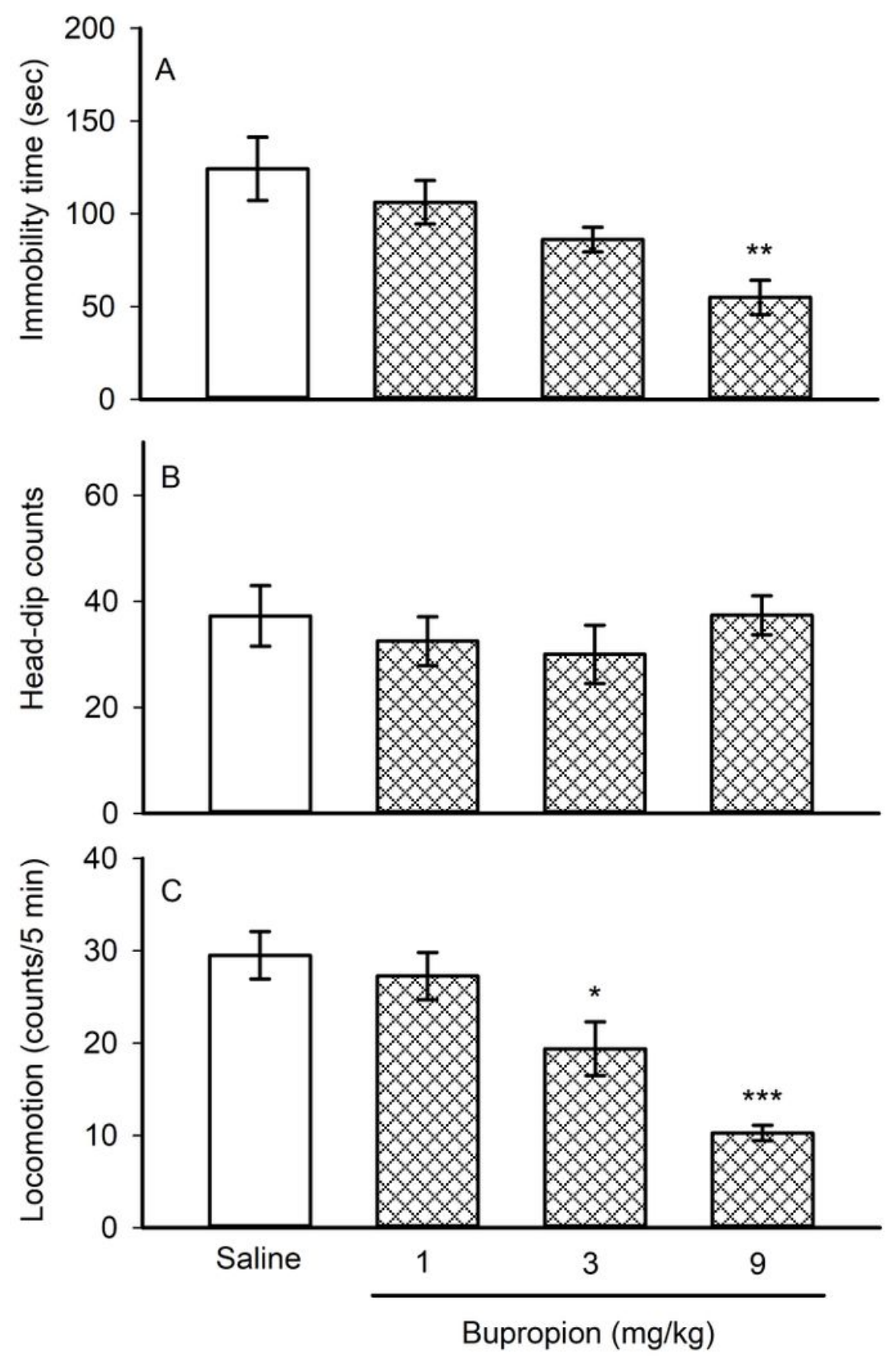

Fig. 2

Figure 2

Effect of bupropion on mice performance in the FST and hole-board apparatus. Bupropion (1, 3 and 9 $\mathrm{mg} / \mathrm{kg}$; i.p.) was administered i.p. $30 \mathrm{~min}$ before the behavioral tests. Control animals received saline (10 $\mathrm{ml} / \mathrm{kg}$, i.p.). (A) immobility time in the FST, (B) head-dip counts and (C) locomotor activity in the holeboard apparatus. Bars represented means \pm SEM of eight mice. ${ }^{\star \star \star} P<0.001,{ }^{\star}{ }^{*} P<0.01$, and ${ }^{*} P<0.5$ versus saline group according to one-ANOVA followed by Tukey post-hoc test. 

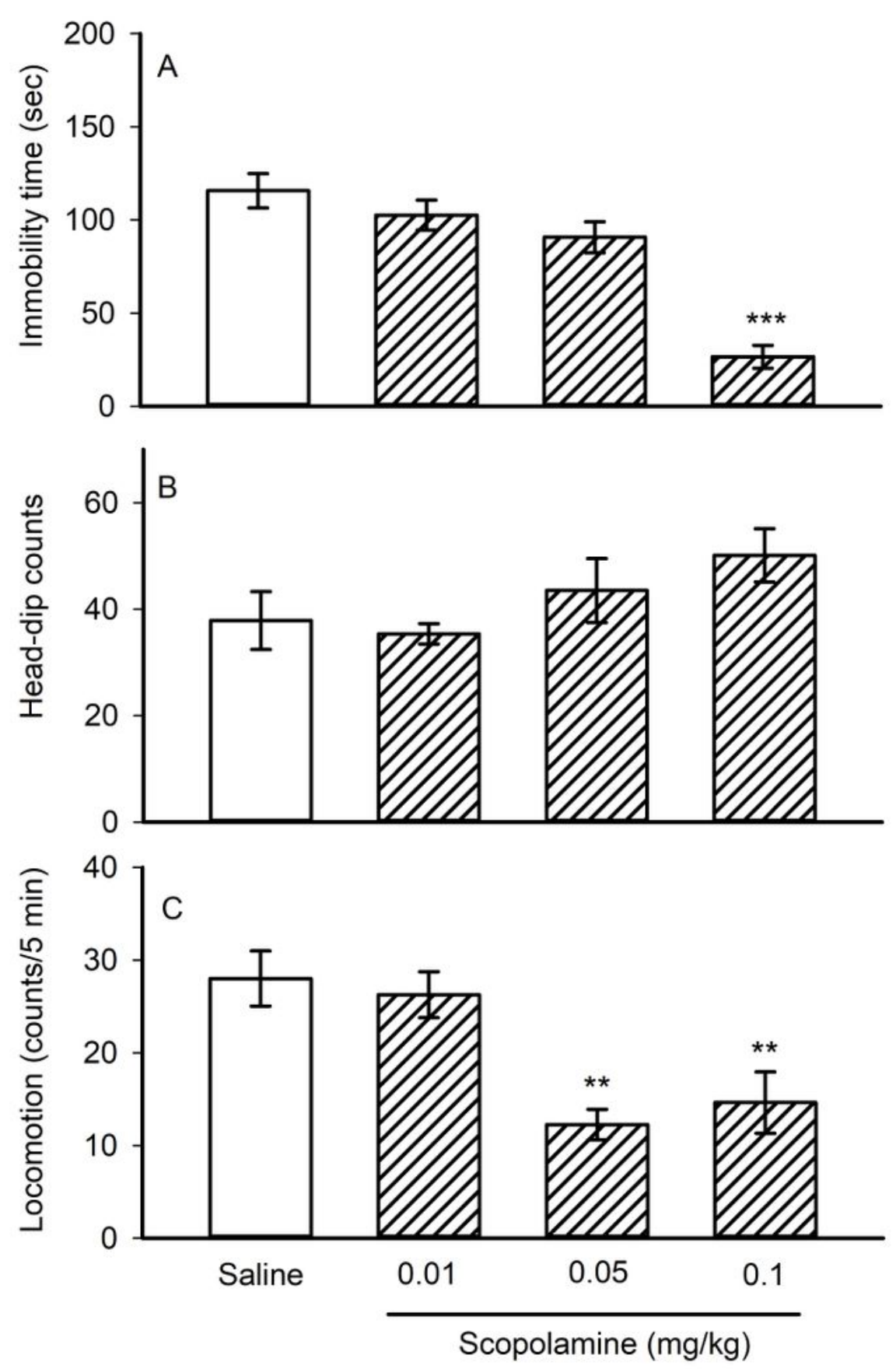

Fig. 3

\section{Figure 3}

Effect of scopolamine on mice performance in the FST and hole-board apparatus. Scopolamine (0.01, 0.05 and $0.1 \mathrm{mg} / \mathrm{kg}$; i.p.) was administered i.p. $30 \mathrm{~min}$ before the behavioral tests. Control animals received saline (10 $\mathrm{ml} / \mathrm{kg}$, i.p.). (A) immobility time in the FST, (B) head-dip counts and (C) locomotor activity in the hole-board apparatus. Bars represented means \pm SEM of eight mice. ${ }^{\star \star *} \mathrm{P}<0.001$ and $* \star P<$ 0.01 versus saline group according to one-ANOVA followed by Tukey post-hoc test. 

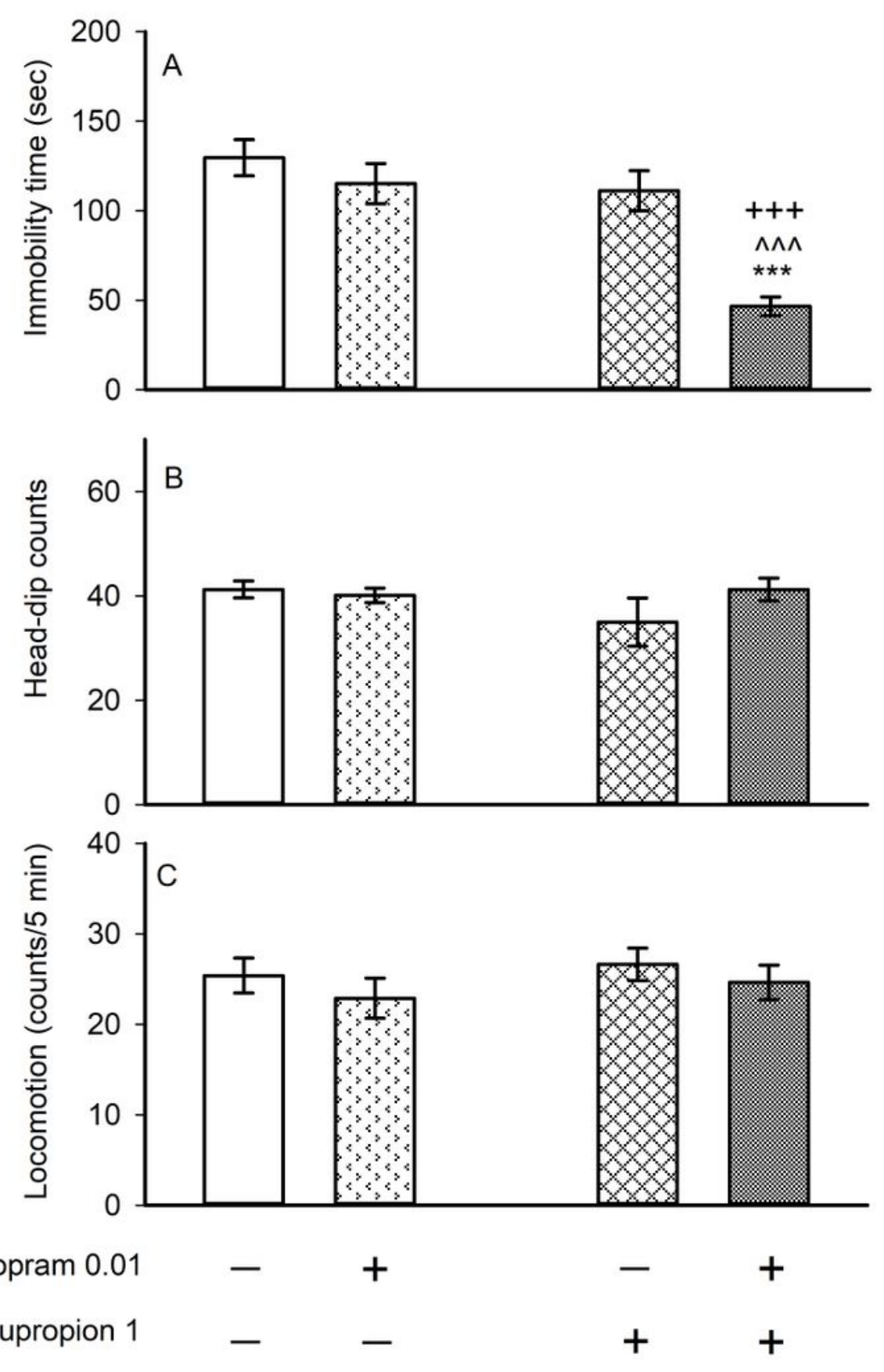

Fig. 4

\section{Figure 4}

Interaction between citalopram and bupropion, at inactive doses, on mice performance in the FST and hole-board apparatus. Citalopram (0.01 mg/kg; i.p.) was co-administered with bupropion ( $1 \mathrm{mg} / \mathrm{kg}$, i.p.) 30 min before the behavioral tests. Control animals received saline/saline. (A) immobility time in the FST, (B) head-dip counts and (C) locomotor activity in the hole-board apparatus. Bars represented means \pm 
SEM of eight mice. ${ }^{\star \star \star} \mathrm{P}<0.001$ versus saline/saline group, ${ }^{\wedge \wedge \wedge} \mathrm{P}<0.001$ versus citalopram/saline group, $+++\mathrm{P}<0.001$ versus bupropion/saline group according to two-ANOVA followed by Tukey post-hoc test.
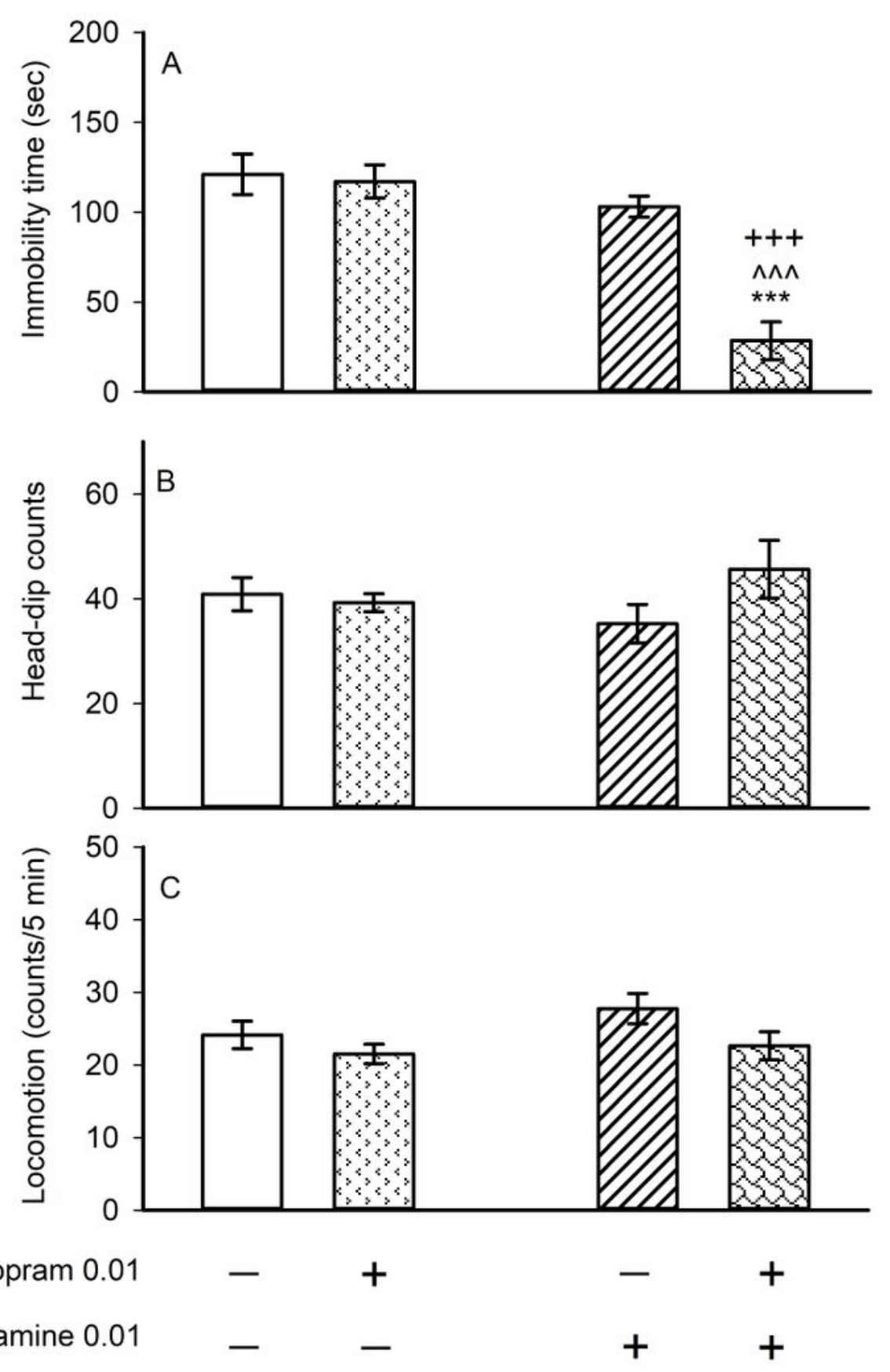

Fig. 5

Figure 5

Interaction between citalopram and scopolamine, at inactive doses, on mice performance in the FST and hole-board apparatus. Citalopram (0.01 mg/kg; i.p.) was co-administered with scopolamine $(0.01 \mathrm{mg} / \mathrm{kg}$, 
i.p.) $30 \mathrm{~min}$ before the behavioral tests. Control animals received saline/saline. (A) immobility time in the FST, (B) head-dip counts and (C) locomotor activity in the hole-board apparatus. Bars represented means \pm SEM of eight mice. ${ }^{* * * P}<0.001$ versus saline/saline group, ${ }^{\wedge \wedge} \mathrm{P}<0.001$ versus citalopram/saline group, $+++P<0.001$ versus scopolamine/saline group according to two-ANOVA followed by Tukey posthoc test.
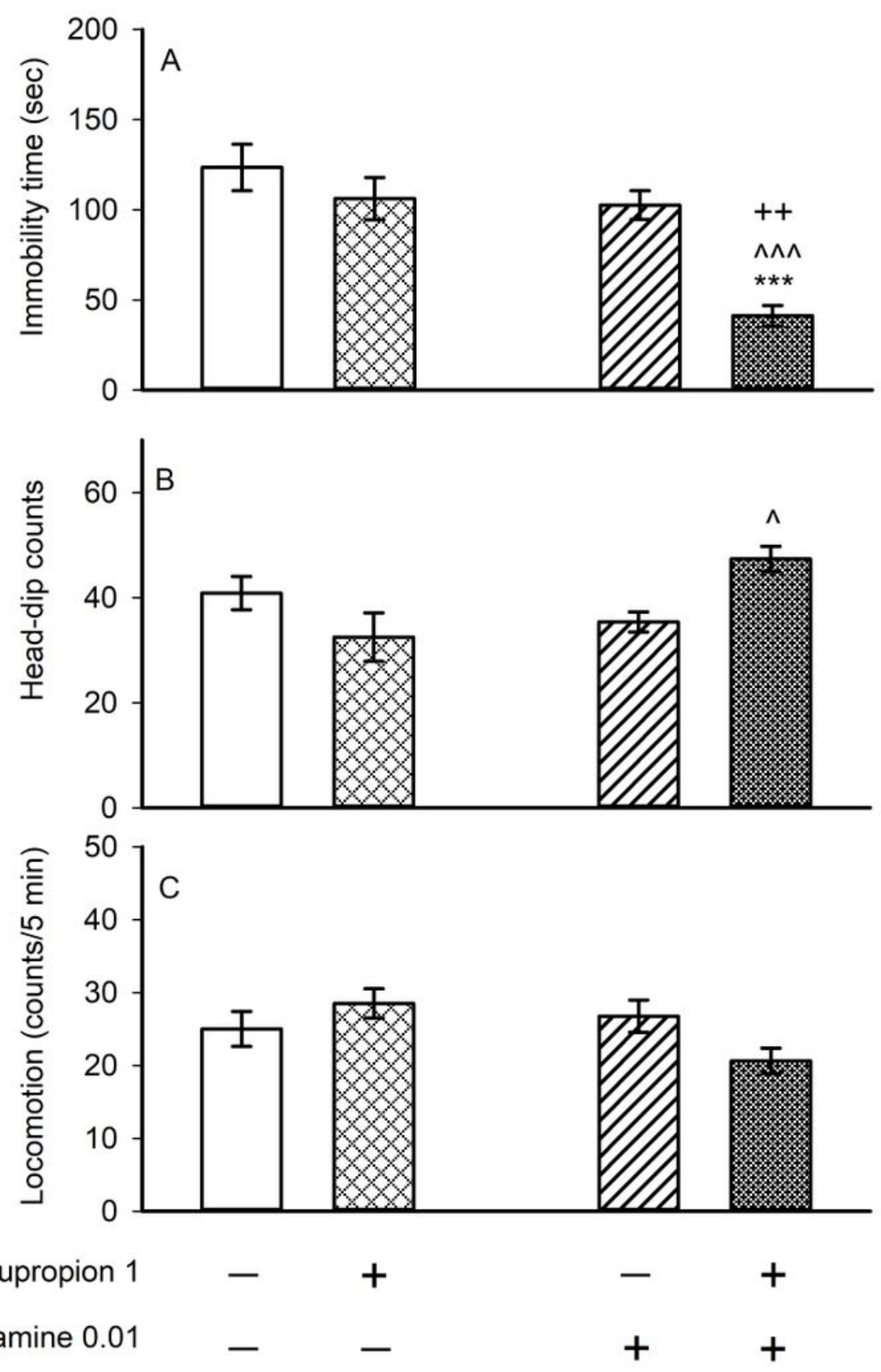

Fig. 6

Figure 6 
Interaction between bupropion and scopolamine, at inactive doses, on mice performance in the FST and hole-board apparatus. Bupropion (1 mg/kg; i.p.) was co-administered with scopolamine $(0.01 \mathrm{mg} / \mathrm{kg}$, i.p.) $30 \mathrm{~min}$ before the behavioral tests. Control animals received saline/saline. (A) immobility time in the FST, (B) head-dip counts and (C) locomotor activity in the hole-board apparatus. Bars represented means \pm SEM of eight mice. ${ }^{\star \star \star} \mathrm{P}<0.001$ versus saline/saline group, ${ }^{\wedge \wedge} \mathrm{P} P 0.001$ versus bupropion/saline group, $++P<0.01$ versus scopolamine/saline group according to two-ANOVA followed by Tukey post-hoc test.

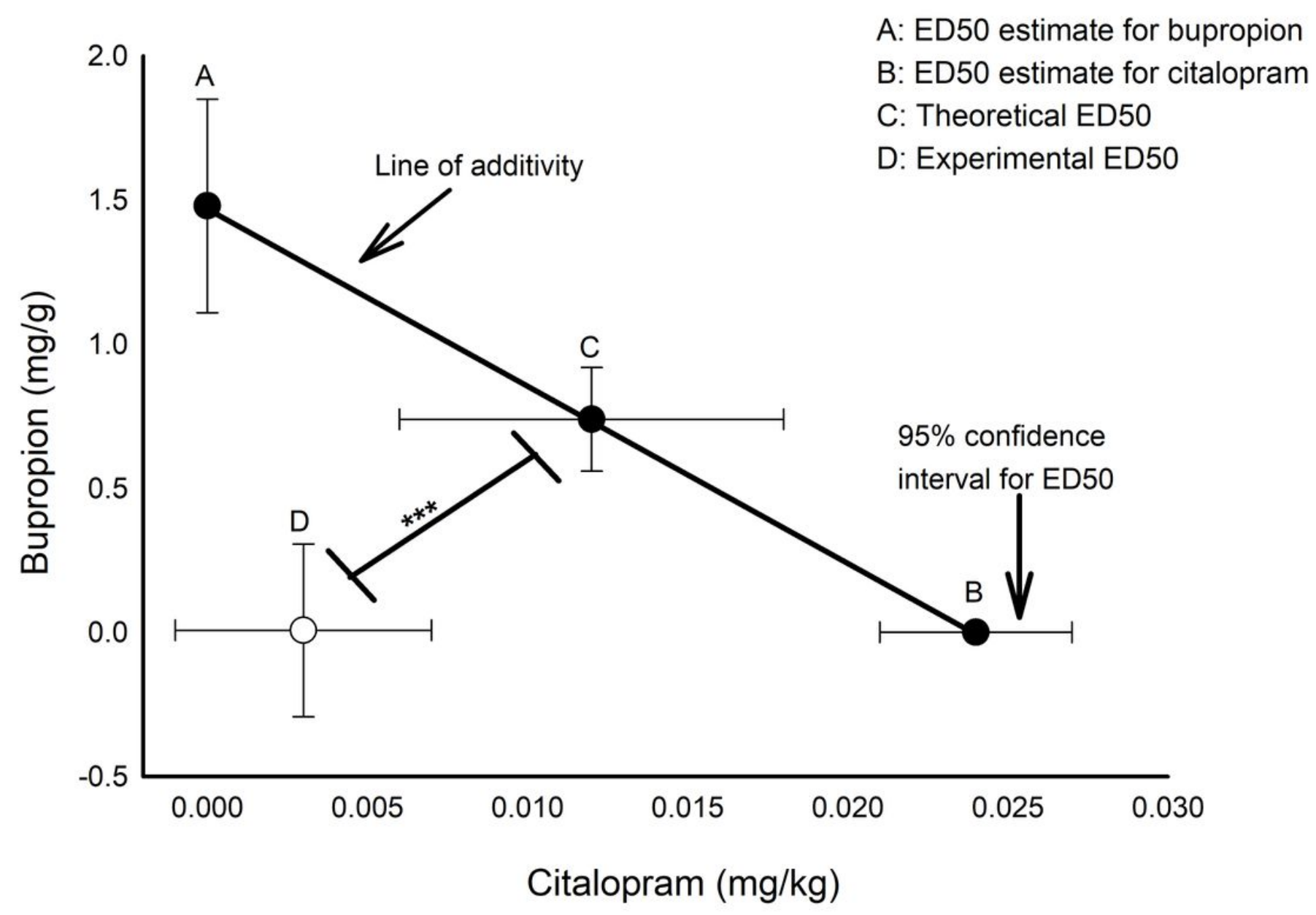

Fig. 7

Figure 7

The synergistic antidepressant effect of a binary combination of citalopram and bupropion in the FST. A significant difference between experimental ED50 (focus D) and theoretical ED50 (focus D) points, proposing a synergistic effect of the drug combination. Foci A and B display the ED50 citalopram and 
bupropion, respectively. The oblique line between $A$ and $B$ is the theoretical additive effect line of citalopram and bupropion combination.

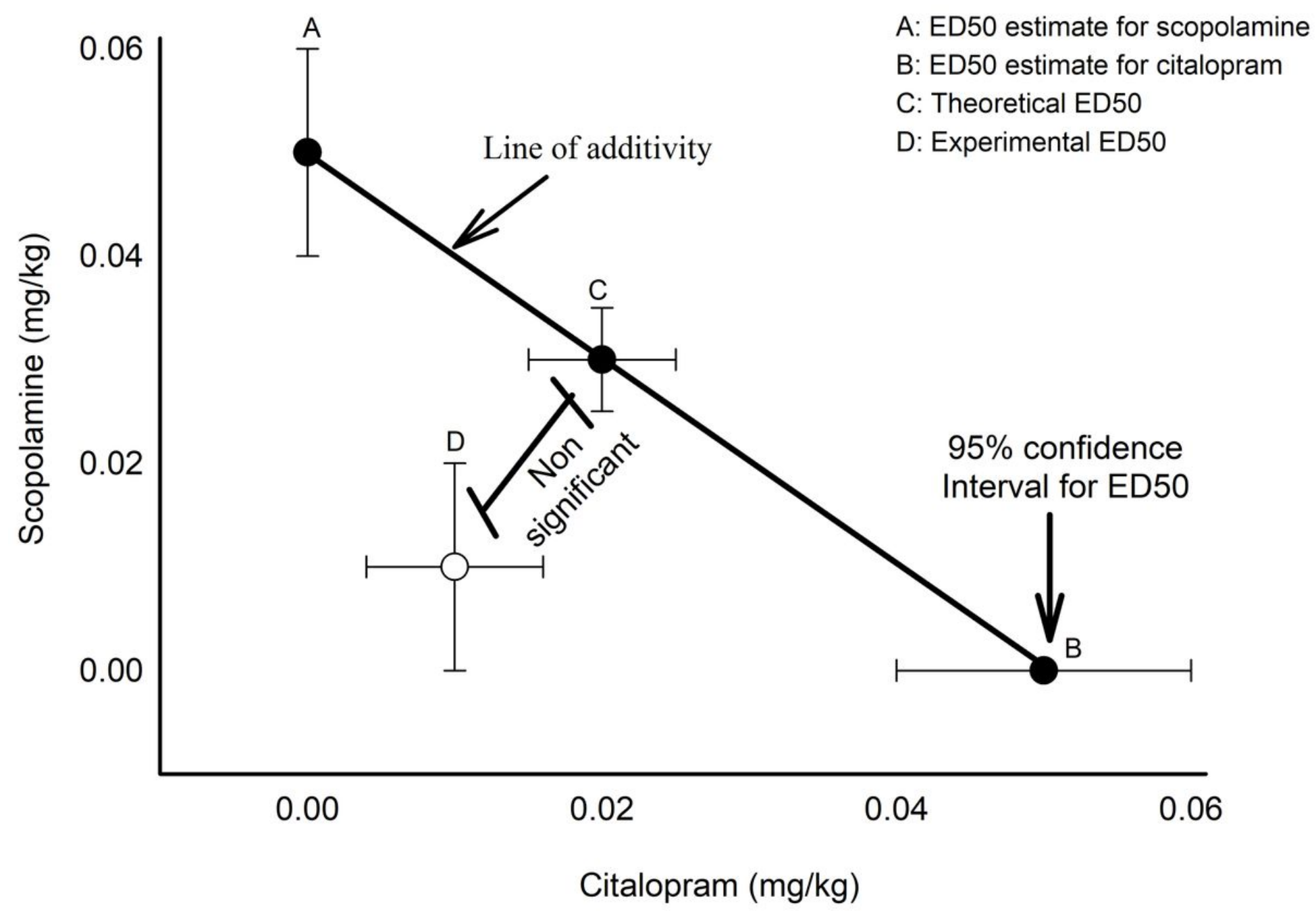

Fig. 8

\section{Figure 8}

The additive antidepressant effect of a binary combination of citalopram and scopolamine in the FST. No significant difference between experimental ED50 (focus D) and theoretical ED50 (focus C) points, suggesting an additive effect of the drug combination. Foci A and B display the ED50 citalopram and 
scopolamine, respectively. The oblique line between $A$ and $B$ is the theoretical additive effect line of citalopram and scopolamine combination.

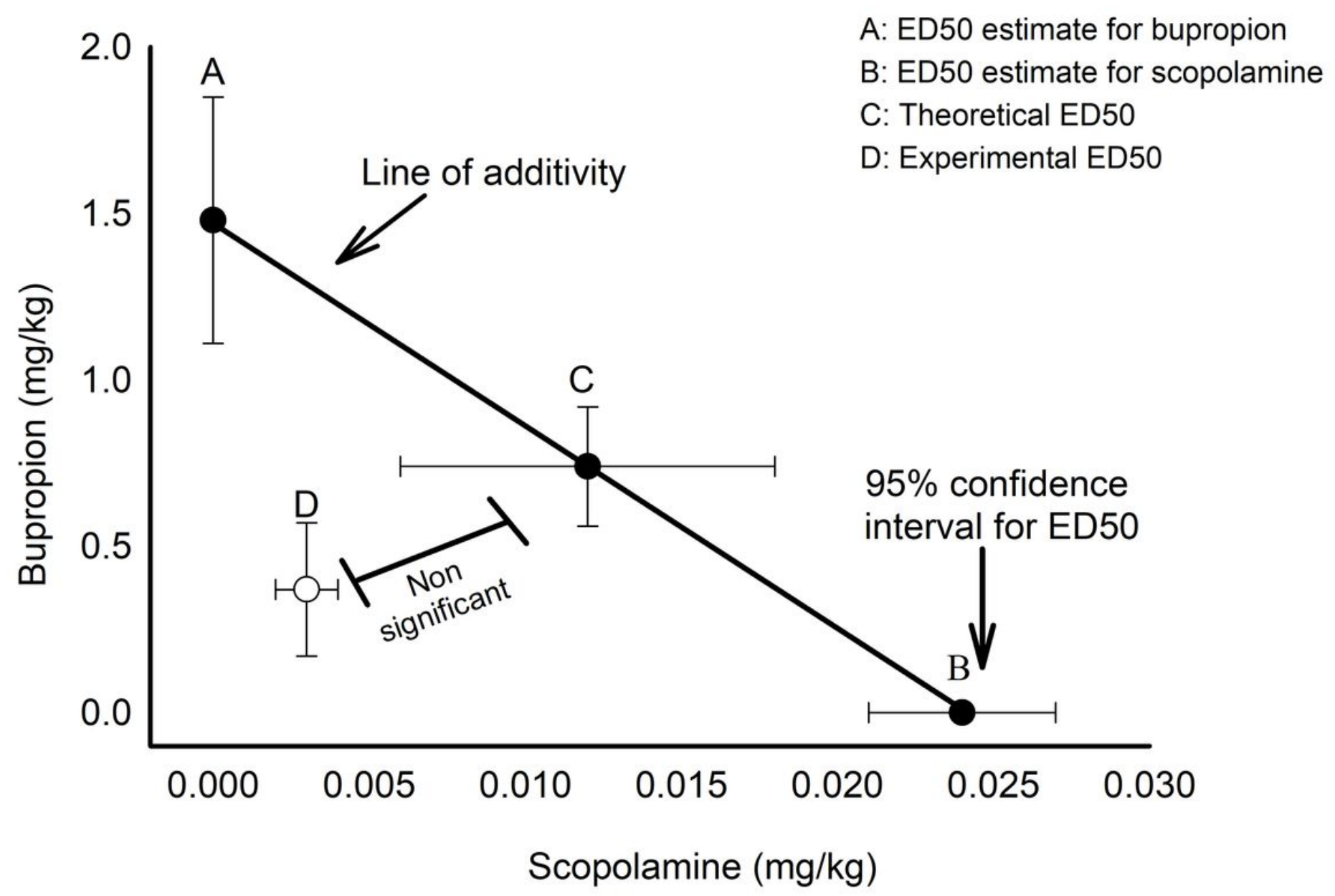

Fig. 9

Figure 9

The additive antidepressant effect of a binary combination of bupropion and scopolamine in the FST. No significant difference between experimental ED50 (focus D) and theoretical ED50 (focus C) points, suggesting an additive effect of the drug combination. Foci $A$ and $B$ display the ED50 bupropion and scopolamine, respectively. The oblique line between $A$ and $B$ is the theoretical additive effect line of bupropion and scopolamine combination.

\section{Supplementary Files}


This is a list of supplementary files associated with this preprint. Click to download.

- RawData.pdf 